\section{US environmentalists must turn out to vote}

Nico Stehr rightly argues that democracy is crucial in the fight against global warming, attributing the inadequate response of most democracies to an overall lack of public engagement (Nature 525, 449-450; 2015). Our findings at the Environmental Voter Project indicate that a contributory factor could be a lamentably low turnout by environmentalist voters.

The Environmental Voter Project is a non-partisan, non-profit organization (www.environmentalvoter. org). We estimate that there could be almost 16 million environmentalists in the United States who rarely or never vote — around 7\% of the country's voting-eligible population.

To arrive at this figure, we brought in data analysts who used a data-rich voter file to create a national predictive modelling survey to identify people with a very high likelihood of believing that climate change is both humaninduced and a crucial issue. They then used public voter files to determine the number in this group who failed to vote in national mid-term elections.

Until many more environmentalists vote, US politicians at least are unlikely to give environmental issues the attention they so badly need.

\section{Nathaniel Stinnett}

Environmental Voter Project, Boston, Massachusetts, USA. nathaniel@environmentalvoter.org

\section{Dutch government appeals climate law}

The Dutch government lodged an appeal last month against The Hague District Court's ruling on 24 June that required it to make more-drastic cuts to the country's greenhouse-gas emissions (see K. Purnhagen Nature 523, 410; 2015). The government's appeal seems to be buying time while the courts decide, which demonstrates the weakness of using lawsuits as a policy tool for climate change.

The climate law has been hailed as marking a new era of environmental activism that could spark similar cases in other countries. Critics have warned against undue politicization of the judiciary, which could inhibit nations from entering into binding international commitments.

The Dutch appeal is likely to be based on the government's right to determine policy, on whether the Kyoto Protocol can have such far-reaching effects and on the way the District Court has defined the state's duty of care. Both parties intend to take the case to the Dutch Supreme Court, which could take several years.

Meanwhile, the government is also awaiting the outcome of several studies before launching any policy proposals. This will not be until next summer at the earliest, so the general elections in March 2017 could offer a faster and more effective means of bringing about policy change. Hanna Schebesta Wageningen University, the Netherlands; and European University Institute, Florence, Italy.

Kai Purnhagen Wageningen University; and Erasmus University Rotterdam, the Netherlands.

kai.purnhagen@wur.nl

\section{Interdisciplinarity: less vague please}

The term 'interdisciplinarity' is used to cover a diversity of practices (see Nature 525, 305; 2015). What is crucial for one kind of interdisciplinarity may be immaterial to another.

Without specificity and differentiation, it is impossible to identify factors essential for success. Relevant features include the nature of the problem under investigation; the number of disciplines involved; whether these are closely aligned or disparate; whether the interdisciplinary research is undertaken by an individual or a team; and whether it is engaged with policy and end-user practice (see go.nature.com/ujwu8g).

I investigated one category of interdisciplinary research, in which experts from multiple, diverse disciplines work with end-users on topical problems, to determine the specialist skills required (see go.nature. com/nnsnsx). Synthesizing knowledge, managing remaining unknowns and supporting policy, practice and technological change are all essential. Each of these skills encompasses an array of concepts and methods.

A new 'interdisciplinary' discipline such as 'integration and implementation sciences' can capture, assess and transmit these skills. It could build a college of peer reviewers to improve quality and raise the visibility and influence of interdisciplinarity.

Gabriele Bammer Australian National University, Acton, Australia.

gabriele.bammer@anu.edu.au

\section{Interdisciplinarity: resources abound}

There is growing international consensus on best practice in interdisciplinary research (see Nature 525, 305; 2015). This has been spurred by various online initiatives.

Transdisciplinarity-net, sponsored by the Swiss Academies of Arts and Sciences, offers a toolkit of useful research strategies (see www.transdisciplinarity.ch/ toolbox). The Association for Interdisciplinary Studies provides many resources, including an 'About interdisciplinarity' section that outlines definitions and best practices (see wwwp.oakland. edu/ais). A set of useful short guides is also available (see go.nature.com/faclve) and the Australian I2S site for integration and implementation sciences provides detailed resources (see i2s.anu.edu.au). The Science of Team Science initiative sponsored by the US National Cancer Institute addresses the particular challenges of conducting research in teams (see www.teamsciencetoolkit. cancer.gov).

Notable among the many books on the topic are Methods for Transdisciplinary Research (Univ. Chicago Press, 2013) by Matthias Bergmann and colleagues and Interdisciplinary Research (Sage, 2011) by Allen Repko.

Because interdisciplinarity is still an emerging approach, such recommendations need reviewing and updating regularly if its potential is to be realized - by those who do interdisciplinary research and by those who study its progress. Rick Szostak University of Alberta, Edmonton, Canada. rszostak@ualberta.ca

\section{Deposited grants buy time in Brazil}

Academics who are paralysed by Brazil's political and financial crisis should take heart (see Nature 526, 16-17; 2015). Funds approved for 2014 by the National Council for Scientific and Technological Development, the country's most important funding agency, were fully deposited and are available to principal investigators until 2016 or, in some cases, 2017.

It is crucial, however, that these resources are managed and used wisely. Coordinators must honour their original funding agreements for designated projects.

These guarantees would buy enough time for President Dilma Rousseff to help to restore Brazil's long-standing record of growing and consistent investment in research. João Ricardo Mendes de Oliveira Federal University of Pernambuco, Recife, Brazil. joao.ricardo@ufpe.br 